\title{
Agro-Healing Service Quality Analysis Using IPA Analysis for Business Owners
}

\author{
Yun-Jin Kim ${ }^{1}$, Seon-Ok Kim², and Sin-Ae Park ${ }^{3,4^{*}}$ \\ ${ }^{1}$ Master Student, Department of Bio \& Healing Convergence, Graduate School, Konkuk University, Seoul, Republic of Korea \\ ${ }^{2}$ Ph.D. Candidate, Department of Bio \& Healing Convergence, Graduate School, Konkuk University, Seoul, Republic of Korea \\ ${ }^{3}$ Assistant Professor, Department of Systems Biotechnology, Konkuk Institute of Technology, Konkuk University, Seoul, Republic of Korea \\ ${ }^{4}$ Assistant Professor, Department of Bio \& Healing Convergence, Graduate School, Konkuk University, Seoul, Republic of Korea
}

\section{ABSTRACT}

Background and objective: This study seeks to investigate domestic agro-healing farm resources so that preliminary data can be obtained on the systematic provisions for agro-healing programs in order to improve service quality and to identify the quality of agro-healing policy services.

Methods: For this study, owners of agro-healing facilities were asked 24 questions via an online survey. An importanceperformance analysis (IPA) was conducted to identify service quality for each policy sector.

Results: Respondents' satisfaction levels were low when compared to agro-healing farm owners' perceptions of the above-average importance of each sector. The results from the resource analysis of domestic agro-healing farms indicated that the main operational purposes of farms were, in descending order, experience (90.0\%), healing (86.7\%), and education (84.0\%). With respect to the type of program that was operated, cultivating crops (horticultural therapy) was identified most frequently at $83.3 \%$.

Conclusion: As a result of this study, the resources possessed by agro-healing farms were identified. In addition, the results of the IPA analysis in terms of service quality are not as good as expected, and performance levels should be increased to improve this. The results of this study are expected to provide useful information not only to improve the quality of agro-healing services, but also to revitalize the agro-healing industry while developing a systematic agro-healing program.

Keywords: agro-healing farm, care farm, green care, priority analysis, resource analysis

\section{Introduction}

Recently, to solve social problems, various agricultural forms have been proposed that hold pluralistic functions, such as those that focus on the healing function of agricultural resources. Agriculture, which has focused on production and tourism in the past, has been transformed due to new trends (RDA, 2012). As an example, social agriculture and agro-healing have emerged based on the pluralistic functions of agriculture. Social agriculture is agri- culture that provides various social services to the underprivileged, and it creates social and economic value for agriculture, and provides positive effects to service recipients and society (Lim and Lim, 2017). Agro-healing pertains to all agricultural activities provided by utilizing agricultural and rural resources to restore, maintain, and promote health for all citizens. In Korea, the Act on Research, Development and Promotion of Healing Agriculture was enacted in March 2020. The government is preparing to build 234 agro-healing facilities and two agro-healing cen-

The research was funded by grant no. PJ016144022021 from the Rural Development Administration in Korea.

Received: December 8, 2021, Revised: December 14, 2021, Accepted: December 15, 2021

First author: Yun-Jin Kim, E-mail: jenny980127@naver.com, (D) https://orcid.org/0000-0002-3071-9513

*Corresponding author: Sin-Ae Park, sapark42@konkuk.ac.kr, (1) https://orcid.org/0000-0003-1367-8825 
ters in certain cities and provinces from 2017 to 2021 in order to build agro-healing infrastructure, an agro-healing diffusion center, and a comprehensive platform for agro-healing in 2021 (Jang et al., 2021).

Most agro-healing farms in Korea are converted from production or experiential farms. The Rural Development Administration of South Korea (RDA, 2017) suggested that in order to develop and provide a systematic agro-healing program for professionals, such as for agro-healing farm owners and agro-healing experts who wish to operate an agro-healing program, then an analysis of farm resources should be prioritized. The core resources of agro-healing farms include plant and animal resources, non-agricultural activities, and natural scenery. It is thus possible to offer a successful agro-healing program by identifying the types of resources possessed by the agro-healing farm (RDA, 2020), particularly since the types of available resources can inform the activities offered by the agro-healing program. Therefore, to develop a customized agro-healing program, the resource analysis process undertaken by agro-healing farms should be prioritized, as it will affect the agro-healing service quality of agro-healing farms.

In Korea, interest in agro-healing has recently increased, but data on agro-healing-related service quality, public awareness, demand, and national policies and support measures, are generally insufficient (Park et al., 2017). The evaluation of service quality reflects the difference between the expected and perceived service (Gronroos, 1984). The importance of service quality has been proven through previous studies in various fields (Kozak and Rimmington, 2000; Orel and Kara, 2014; Su et al., 2016, 2017); however, research on agro-healing service quality remains insufficient. Therefore, it is necessary to evaluate the service quality of agro-healing policies, and based on this, there is a need for quality management policies on agro-healing services.

Therefore, this study was conducted to collect preliminary data on the development of a systematic agro-healing program, while evaluating the service quality of agro-healing farms, as based on the agro-healing farm owners' perceptions. The resources possessed by domestic agro-healing farms were identified, the importance-performance analysis (IPA) was conducted, and agro-healing service design quality was evaluated. These elements can be utilized to improve the quality of agro-healing services while achieving the goals of agro-healing.

\section{Research Methods}

\section{Study respondents and survey methods}

To analyze the available resources and service quality associated with agro-healing policies, a total of 30 agro-healing farm owners were asked to complete an online survey between May 29 and July 23, 2021 (a total of 56 days). In all, 200 agro-healing farm owners were asked to complete the online survey and were recruited through nationwide agricultural technology centers using cluster sampling. A total of 43 completed surveys were collected, and the data from 30 questionnaires were used for the final analysis; in all, 13 questionnaires were omitted. This study was approved by the Institutional Review Board of Konkuk University (7001355-202104-HR-432).

\section{Assessments}

A total of 24 questions were developed to investigate the status of resources in the agro-healing farm industry, while the IPA of agro-healing farm policy services to domestic agro-healing farm owners was performed. The questionnaire consisted of 14 questions related to the resource status of agro-healing farms, 5 questions on the design of the agro-healing service policies, and 5 demographic questions. Agro-healing farm resource questions were subdivided into characteristics, operation status, environmental resources, and activity type (Lee et al., 2018a; Jeong et al., 2017). The questions pertaining to the general characteristics of the farm covered the factors of 'area,' 'facilities' and 'operation period.' The operation status questions covered the factors of the 'purpose of operation,' 'agro-healing program,' 'program duration per session,' 'time per session,' 'number of program operation sessions,' 'operating period' and 'primary participants.' Questions on environmental resources and activity resources covered the factors of 'environmental resources (plant resources, animal resources, non-agricultural activities, and natural scenery)' and 'activity resources by type (farming therapy, horticul- 


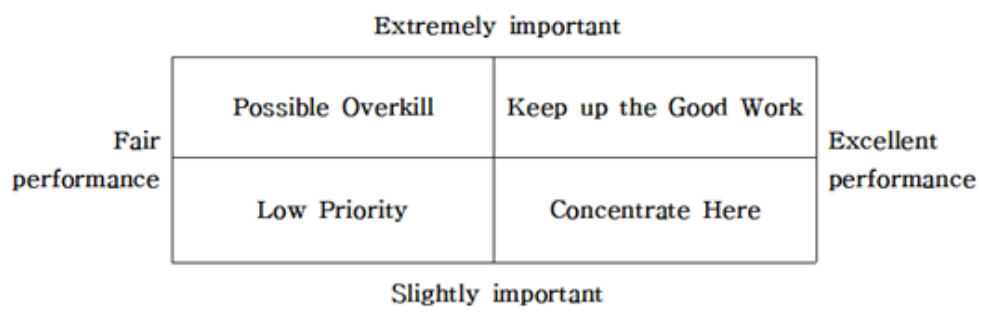

Fig. 1. Overview of the IPA chart (Martilla and James, 1977).

tural therapy, forest healing, and animal-assisted therapy).' The policy service design section consisted of five categories: 'improving accessibility,' 'improving the method of information promotion and provision,' 'diversification of facility and program,' 'financial support' and 'expansion of experts and specialized institutions' (Bae et al., 2019). As a result of calculating the Cronbach's $\alpha$ coefficient of the measurement variables used, all items except 'improving accessibility' showed a high confidence level of 0.80 or higher.

\section{Analysis method}

In this study, descriptive statistics were calculated and reported for the questionnaire data using Microsoft Excel (Office 2007; Microsoft Corp., Redmond, WA, USA) to examine the resource status of agro-healing farms, as well as to summarize the demographic information. In addition, a reliability test was conducted for the IPA questions related to the design of agro-healing service policies using SPSS (Ver. 28 for Windows; IBM Corp., Armonk, NY, USA), a statistical software package.

IPA was conducted for the design of the agro-healing service policies. IPA is a technique developed in the field of marketing to simultaneously analyze how importance and performance are perceived with respect to certain important attributes of a provided service or project (Martilla and James, 1977). The analysis result measures the importance and performance of the evaluated element, displays it on a two-dimensional drawing, and examines it according to its location (Fig. 1). IPA is displayed as quadrants, which are divided by the center point as 'Keep up the Good Work,' 'Possible Overkill,' 'Low Priority' and 'Concentrate Here,' respectively. 'Keep up the Good
Work' means that the element is of high importance, that performance is relatively good, and that it is desirable to keep it. 'Possible Overkill' means that it is okay to reduce or cease performance when insignificant elements are overperforming. 'Low Priority' indicates that both importance and performance are low. 'Concentrate Here' is high in importance but low in performance, meaning that it is a point of focus for future improvement. IPA is useful for identifying areas that need improvement based on policy awareness (Slack, 1994). In this study, the four quadrants were divided and displayed on three points, reflecting the median value of a 5-point Likert scale (1-5) (Bae et al., 2019).

\section{Results and Discussion}

\section{Respondents' demographic information}

In terms of gender, $53.3 \%$ of the respondents were female and $46.7 \%$ were male (Table 1). Further, with respect to age, $56.7 \%$ were in their $50 \mathrm{~s}, 20.0 \%$ were in their $40 \mathrm{~s}, 13.3 \%$ were in their $60 \mathrm{~s}, 6.7 \%$ were in their $30 \mathrm{~s}$, and $3.3 \%$ were younger than 30 . The residential districts represented in this study included Gyeonggi-do (26.7\%), Chungcheongnam-do (including Sejong; 23.3\%), Gangwon-do and Jeollabuk-do (10.0\%), Seoul and Jeju (6.7\%), and Busan, Daegu, Daejeon, and Chungcheongbuk-do (3.3\%). As for educational backgrounds, respondents were most likely to be university graduates, who represented $76.7 \%$ of all respondents. Further, 10 respondents (33.3\%) majored in agriculture (e.g., horticulture, animal husbandry, and forestry) and humanities, and 2 respondents $(6.7 \%)$ majored in engineering and technology. 
Table 1. Demographic information of the agro-healing farm owners who participated in this study

\begin{tabular}{|c|c|c|c|}
\hline Variable & Category & $\mathrm{N}$ & $\%$ \\
\hline \multirow{2}{*}{ Gender } & Male & 14 & 46.7 \\
\hline & Female & 16 & 53.3 \\
\hline \multirow{5}{*}{ Age } & Less than 30 years old & 1 & 3.3 \\
\hline & 31 to 40 years old & 2 & 6.7 \\
\hline & 41 to 50 years old & 6 & 20.0 \\
\hline & 51 to 60 years old & 17 & 56.7 \\
\hline & Over 61 years old & 4 & 13.3 \\
\hline \multirow{10}{*}{ Operating area } & Seoul & 2 & 6.7 \\
\hline & Busan & 1 & 3.3 \\
\hline & Daegu & 1 & 3.3 \\
\hline & Daejeon & 1 & 33 \\
\hline & Gyeonggi-do & 8 & 26.7 \\
\hline & Gangwon-do & 3 & 10.0 \\
\hline & Chungcheongbuk-do & 1 & 3.3 \\
\hline & Chungcheongnam-do (including Sejong) & 7 & 23.3 \\
\hline & Jeollabuk-do & 3 & 10.0 \\
\hline & Jeju-do & 2 & 6.7 \\
\hline \multirow{3}{*}{ Education } & High school graduate & 1 & 3.3 \\
\hline & University graduate & 23 & 76.7 \\
\hline & Graduate school graduate & 6 & 20.0 \\
\hline \multirow{4}{*}{ Major } & Agriculture & 10 & 33.3 \\
\hline & Engineering and technology & 2 & 6.7 \\
\hline & Humanities & 10 & 33.3 \\
\hline & Others & 8 & 26.7 \\
\hline
\end{tabular}

\section{Characteristics of agro-healing farms}

The operating area of the largest group of agro-healing farms was Gyeonggi-do (30.0\%), followed by Sejong (16.7\%), Gangwon-do and Jeollabuk-do (10.0\%), Chungcheongbuk-do and Chungcheongnam-do and Jeju-do (6.7\%), Seoul and Busan and Daegu and Daejeon (3.3\%) (Table 2). In terms of the scale of the agro-healing farms, $50.0 \%$ were over $9,900 \mathrm{~m}^{2} ; 16.7 \%$ were under $1,650 \mathrm{~m}^{2} ; 10.0 \%$ were 8,300 $\mathrm{m}^{2}$ to $9,900 \mathrm{~m}^{2} ; 6.7 \%$ each were in the ranges of 1,650 $\mathrm{m}^{2}$ to $3,300 \mathrm{~m}^{2}, 3,300 \mathrm{~m}^{2}$ to $5,000 \mathrm{~m}^{2}$, and $6,600 \mathrm{~m}^{2}$ to $8,300 \mathrm{~m}^{2}$; and $3.3 \%$ were $5,000 \mathrm{~m}^{2}$ to $6,600 \mathrm{~m}^{2}$. In terms of facility type, the agro-healing farms were crop-harvesting facilities $(90.0 \%)$, educational facilities $(73.3 \%)$, harvest sales facilities (43.3\%), forests $(26.7 \%)$, kitchen and cooking facilities $(23.3 \%)$, and lodging facilities (13.3\%). The operating periods for these farms were as follows: more than 11 years $(33.3 \%), 3$ to 5 years $(30.0 \%), 6$ to 10 years $(23.3 \%)$, and less than 1 year and 1 to 2 years (6.7\% each).

In the UK, a survey of 115 agro-healing farms in operation since 2012 was conducted, and it was determined that the farm area ranged from 4,000-6,480,000 $\mathrm{m}^{2}$ (Bragg, 2013), which is a relatively wide range and indicates a larger scale when compared to the agro-healing farms of Korea. This was believed to be because most of the agro-healing farms in Europe are operated as grassland-based dairy farms, unlike domestic agro-healing farms, which are mainly operated as crop-cultivation facilities or educational facilities (Hassink et al., 2020).

\section{Operation status}

In descending order, the most common facility operation 
Table 2. Characteristics of the agro-healing farms in this study

\begin{tabular}{|c|c|c|c|}
\hline Variable & Category & $\mathrm{N}$ & $\%$ \\
\hline \multirow{11}{*}{ Operating area } & Seoul & 1 & 3.3 \\
\hline & Busan & 1 & 3.3 \\
\hline & Daegu & 1 & 3.3 \\
\hline & Daejeon & 1 & 3.3 \\
\hline & Sejong & 5 & 16.7 \\
\hline & Gyeonggi-do & 9 & 30.0 \\
\hline & Gangwon-do & 3 & 10.0 \\
\hline & Chungcheongbuk-do & 2 & 6.7 \\
\hline & Chungcheongnam-do & 2 & 6.7 \\
\hline & Jeollabuk-do & 3 & 10.0 \\
\hline & Jeju-do & 2 & 6.7 \\
\hline \multirow{7}{*}{ Scale } & Less than $1,650 \mathrm{~m}^{2}$ & 5 & 16.7 \\
\hline & $1,650-3,300 \mathrm{~m}^{2}$ & 2 & 6.7 \\
\hline & $3,300-5,000 \mathrm{~m}^{2}$ & 2 & 6.7 \\
\hline & $5,000-6,600 \mathrm{~m}^{2}$ & 1 & 3.3 \\
\hline & $6,600-8,300 \mathrm{~m}^{2}$ & 2 & 6.7 \\
\hline & $8,300-9,900 \mathrm{~m}^{2}$ & 3 & 10.0 \\
\hline & More than $9,900 \mathrm{~m}^{2}$ & 15 & 50.0 \\
\hline \multirow{7}{*}{$\begin{array}{c}\text { Facilities } \\
\text { (multiple responses) }\end{array}$} & Cultivating crops facility & 27 & 90.0 \\
\hline & Lodging facilities & 4 & 13.3 \\
\hline & Educational facility & 22 & 73.3 \\
\hline & Kitchen and cooking facilities & 7 & 23.3 \\
\hline & Animal breeding facility & 9 & 30.0 \\
\hline & Forests & 8 & 26.7 \\
\hline & Harvest sales facility & 13 & 43.3 \\
\hline \multirow{5}{*}{ Operating period } & Less than 1 years & 2 & 6.7 \\
\hline & 1 to 2 years & 2 & 6.7 \\
\hline & 3 to 5 years & 9 & 30.0 \\
\hline & 6 to 10 years & 7 & 23.3 \\
\hline & More than 11 years & 10 & 33.3 \\
\hline
\end{tabular}

purposes included the following: experience $(90.0 \%)$, healing (86.7\%), education (80.0\%), agriculture/production (60.0\%), processing/sales (46.7\%), and rehabilitation (16.7\%; Table 3). In terms of the most commonly reported agro-healing programs, cultivating crops (horticultural therapy) were frequently reported $(83.3 \%)$, followed by harvesting crops (76.7\%), cooking with the harvest $(50.0 \%)$, indoor horticultural activity (36.7\%), harvested crop processing (33.3\%), forest healing and animal experience (26.7\%), and livestock processing $(3.3 \%)$. In terms of program duration, the respondents indicated that the agro-healing sessions tended to be held on one day (96.7\%), and the time per session was mostly over 90 minutes, or between 60 to 90 minutes. The agro-healing farms were mostly operated during the spring and autumn: in April (90.0\%), May (90.0\%), June (86.7\%), September (86.7\%), October $(90.0 \%)$, and November $(73.3 \%)$. The most frequently reported participants in the agro-healing agriculture programs were members of the general public $(100.0 \%)$. When the general public was excluded from the analysis, the primary participants also included those in the field of education $(73.3 \%)$, those who were training for employment $(20.0 \%)$, those who were undergoing rehabilitation and or treatment for physical diseases (10.0\%), and those living with mental illness (16.7\%). 
Table 3. The factors influencing agro-healing farm operations (multiple responses)

$(n=30)$

\begin{tabular}{|c|c|c|c|}
\hline Variable & Category & $\mathrm{N}$ & $\%$ \\
\hline \multirow{6}{*}{ Purpose of operation } & Education & 24 & 80.0 \\
\hline & Experience & 27 & 90.0 \\
\hline & Healing & 26 & 86.7 \\
\hline & Rehabilitation & 5 & 16.7 \\
\hline & Agriculture/production & 18 & 60.0 \\
\hline & Processing/sales & 14 & 46.7 \\
\hline \multirow{8}{*}{ Agro-healing program } & Cultivating crops & 25 & 83.3 \\
\hline & Harvesting crops & 23 & 76.7 \\
\hline & Cooking with the harvest & 15 & 50.0 \\
\hline & Indoor horticultural activity & 11 & 36.7 \\
\hline & Forest healing & 8 & 26.7 \\
\hline & Processing with harvesting crop & 10 & 33.3 \\
\hline & Animal experience & 8 & 26.7 \\
\hline & Livestock processing & 1 & 3.3 \\
\hline \multirow{4}{*}{$\begin{array}{l}\text { Program duration } \\
\text { per one session }\end{array}$} & Daily & 29 & 96.7 \\
\hline & 1 Night 2 Days & 7 & 23.3 \\
\hline & 2 Nights 3 Days & 1 & 3.3 \\
\hline & More than 4 days & 2 & 6.7 \\
\hline \multirow{3}{*}{ Time per one session } & 30 to 60 minutes & 7 & 23.3 \\
\hline & 60 to 90 minutes & 15 & 50.0 \\
\hline & Over 90 minutes & 16 & 53.3 \\
\hline \multirow{4}{*}{$\begin{array}{c}\text { Number of program } \\
\text { sessions }\end{array}$} & Less than 4 session & 22 & 73.3 \\
\hline & 5 to 8 session & 7 & 23.3 \\
\hline & 9 to 10 session & 1 & 3.3 \\
\hline & 11 to 14 session & 2 & 6.7 \\
\hline \multirow{12}{*}{ Operating period } & January & 9 & 30.0 \\
\hline & February & 11 & 36.7 \\
\hline & March & 20 & 66.7 \\
\hline & April & 27 & 90.0 \\
\hline & May & 27 & 90.0 \\
\hline & June & 26 & 86.7 \\
\hline & July & 19 & 63.3 \\
\hline & August & 17 & 56.7 \\
\hline & September & 26 & 86.7 \\
\hline & October & 27 & 90.0 \\
\hline & November & 22 & 73.3 \\
\hline & December & 15 & 50.0 \\
\hline \multirow{6}{*}{ Participants } & General public & 30 & 100.0 \\
\hline & Training for employment & 6 & 20.0 \\
\hline & Education & 22 & 73.3 \\
\hline & Training for rehabilitation & 3 & 10.0 \\
\hline & Physical disease patient & 3 & 10.0 \\
\hline & Mentally ill patient & 5 & 16.7 \\
\hline
\end{tabular}

As of 2018, the purpose of farm operations was investigated for 78 educational and experience farms in Korea. The owners of the agro-healing farms accounted for only $47.4 \%$ of the total respondents (Lee et al., 2018b). It was postulated that the provision of services for agro-healing purposes has increased based on changes in farm owners' perceptions of agro-healing through the operation of related supporting projects and the establishment of infrastructure following the en- 
Table 4. Environmental resources of domestic healing farms (multiple responses)

\begin{tabular}{|c|c|c|c|}
\hline Variable & Category & $\mathrm{N}$ & $\%$ \\
\hline \multirow{6}{*}{ Plant resource } & Vegetable & 23 & 76.7 \\
\hline & Flower & 11 & 36.7 \\
\hline & Herb & 13 & 43.3 \\
\hline & Fruit tree & 21 & 70.0 \\
\hline & Food crop & 20 & 66.7 \\
\hline & Medicinal crop & 11 & 36.7 \\
\hline \multirow{10}{*}{ Animal resource } & Horse & 1 & 3.3 \\
\hline & Dog & 14 & 46.7 \\
\hline & Rabbit & 10 & 33.3 \\
\hline & Sheep & 2 & 6.7 \\
\hline & Goat & 3 & 10.0 \\
\hline & Cat & 8 & 26.7 \\
\hline & Fish & 7 & 23.3 \\
\hline & Reptile & 2 & 6.7 \\
\hline & Bird & 9 & 30.0 \\
\hline & Insect & 6 & 20.0 \\
\hline \multirow{6}{*}{$\begin{array}{c}\text { Non-agricultural } \\
\text { activity }\end{array}$} & Cooking with the harvest & 16 & 53.3 \\
\hline & Tea ceremony & 5 & 16.7 \\
\hline & Crafts & 7 & 23.3 \\
\hline & Farm-based wellness food & 14 & 46.7 \\
\hline & Rural cultural resources & 16 & 53.3 \\
\hline & Processing and selling of agricultural products & 20 & 66.7 \\
\hline \multirow{4}{*}{ Natural scenery } & Small scenery & 17 & 56.7 \\
\hline & Medium scenery & 18 & 60.0 \\
\hline & Large scenery & 16 & 53.3 \\
\hline & Temporary scenery & 17 & 56.7 \\
\hline
\end{tabular}

actment of the agro-healing act (Jang et al., 2021).

In the Netherlands, agro-healing is focused on the education and treatment of mentally ill people, including learning disabilities and autism spectrum disorders, by implementing a system payable through medical fees under the Exceptional Medical Expenses Act (AWBZ) and the Persoonsgebonden Budget (PGB) (Hassink et al., 2014, 2020, CF UK, 2016). On the other hand, in the case of domestic agro-healing farms, the main users were the general public, showing a difference in terms of service consumers from Europe. Accordingly, when examining the number of agro-healing program sessions, most domestic agro-healing farms operated short-term programs of less than 4 sessions; however, in Europe, countries such as the Netherlands and the United Kingdom reported operating longer term programs of 8 months' duration or longer (CF UK, 2016; Hassink et al., 2020). It is hypothesized that there are differences in the goals of service provision and the types of services provided, as based on the difference in the level and nature of domestic and foreign agro-healing farm policy support.

\section{Environmental and activity resources by type}

The environmental resource questions related to the agro-healing farms explored different resources, including plant resources, animal resources, non-agricultural activity, and natural scenery (Table 4). The classification of environmental resources by type was based on the criteria presented by the RDA (2020). Of the environmental resources, 
Table 5. Activity types of domestic agro-healing farms (multiple responses)

\begin{tabular}{|c|c|c|c|}
\hline Variable & Category & $\mathrm{N}$ & $\%$ \\
\hline \multirow{7}{*}{$\begin{array}{l}\text { Agricultural work } \\
\text { healing }\end{array}$} & Creating an animal breeding environment & 8 & 26.7 \\
\hline & Carpentry & 7 & 23.3 \\
\hline & Cleaning around the farm & 9 & 30.0 \\
\hline & Management of mechanical equipment and tools & 15 & 50.0 \\
\hline & Firewood management & 10 & 33.3 \\
\hline & Making processed food & 20 & 66.7 \\
\hline & Other creative activities & 14 & 46.7 \\
\hline \multirow{7}{*}{ Horticultural therapy } & Vegetable garden design & 18 & 60.0 \\
\hline & Creating vegetables garden & 20 & 66.7 \\
\hline & Cultivating the plant & 23 & 76.7 \\
\hline & Vegetable garden management & 20 & 66.7 \\
\hline & Harvesting crop management & 25 & 83.3 \\
\hline & Making crafts using plants & 17 & 56.7 \\
\hline & Farm party & 19 & 63.3 \\
\hline \multirow{5}{*}{ Forest healing } & Walking in the forest & 18 & 60.0 \\
\hline & Meditation in the forest & 15 & 50.0 \\
\hline & Crafts in the forest & 6 & 20.0 \\
\hline & Playing in the forest & 13 & 43.3 \\
\hline & Yoga in the forest & 8 & 26.7 \\
\hline \multirow{5}{*}{$\begin{array}{c}\text { Animal-assisted } \\
\text { therapy }\end{array}$} & Activity with dog & 13 & 43.3 \\
\hline & Activity with rabbit & 9 & 30.0 \\
\hline & Activity with sheep/goat & 1 & 3.3 \\
\hline & Activity for catching fish & 6 & 20.0 \\
\hline & Activity for experiencing insect & 6 & 20.0 \\
\hline
\end{tabular}

plant resources included vegetables $(76.7 \%)$, fruit $(70.0 \%)$, food crops $(66.7 \%)$, herbs $(43.3 \%)$, flowers $(36.7 \%)$, and medicinal crops $(36.7 \%)$. Among the environmental resources, animal resources included dogs $(46.7 \%)$, rabbits (33.3\%), birds (30.0\%), cats $(26.7 \%)$, fish $(23.3 \%)$, insects $(20.0 \%)$, goats $(10.0 \%)$, sheep $(6.7 \%)$, reptiles $(6.7 \%)$, and horses (3.3\%). Among the environmental resources, nonagricultural activities included the processing and selling of agricultural products $(66.7 \%)$, cooking with the harvest (53.3\%), rural cultural resources (53.3\%), farm-based wellness food (46.7\%), crafts $(23.3 \%)$, and tea ceremonies $(16.7 \%)$. Among the environmental resources, natural scenery resources were classified as medium scenery $(60.0 \%)$, small scenery $(56.7 \%)$, temporary scenery $(56.7 \%)$, and large scenery $(53.3 \%)$.

The various activities conducted by the agro-healing farms included the following: agricultural healing work, horticultural therapy, forest healing, and animal-assisted therapy (Table 5). Of the activity types, agricultural healing work included the making of processed food $(66.7 \%)$, the management of mechanical equipment and tools $(50.0 \%)$, other creative activities $(46.7 \%)$, firewood management $(33.3 \%)$, cleaning around the farm $(30.0 \%)$, creating an animal breeding environment (26.7\%), and carpentry (23.3\%). Further, the horticultural therapy activities included the management of crop harvesting (83.3\%), plant cultivation $(76.7 \%)$, the creation and management of vegetable gardens $(66.7 \%)$, farm parties $(63.3 \%)$, vegetable garden design $(60.0 \%)$, and making crafts using plants (56.7\%). Forest healing activities included walking in the forest $(60.0 \%)$, meditation in the forest $(50.0 \%)$, playing in the forest $(43.3 \%)$, yoga in the forest $(26.7 \%)$, and crafts in 
the forest $(20.0 \%)$. Finally, animal-assisted therapy activities included activities with dogs $(43.3 \%)$, activities with rabbits $(30.0 \%)$, activities to experience insects $(23.3 \%)$, fishing (20.0\%), and activities with sheep/goats (3.3\%).

As of 2016, and as a result of a farm-type survey of 614 agro-healing farms in the Netherlands, more than $70 \%$ were found to be primarily operated by dairy farmers (Hassink et al., 2020). This is different from the case in Korea, where agro-healing farms feature different types of resources, such as animal and plant resources, non-agricultural activity resources, and forest resources. In order to develop an agro-healing program, it is a priority for the farmer or expert to identify the resources possessed by the farm (RDA, 2017). In particular, many types of agro-healing farms have been converted from production farms or education/experience farms to agro-healing farms in Korea (Lee et al., 2018b).

\section{IPA results for the design of agro-healing service policies}

The results of the IPA indicated that respondents regarded the importance and performance of agro-healing service policies as above average, and they also recognized the relative importance of improving accessibility, facility and program diversification, and financial support. The importance and performance of the overall agro-healing revitalization policy sector that was surveyed were above average; all respondents indicated that they require support at the 'Keep Up the Good Work' level (Fig. 2). However, through comparing and analyzing the importance and performance levels of tasks for each sector and sub-division, overall performance was found to be relatively low when compared to importance. This means that the service quality is not as good as expected, and it is thus necessary to increase the performance level to improve it.

In Korea, users of agro-healing services primarily live in urban areas. However, due to the nature of agro-healing activities, agro-healing farms are typically located in rural areas, so users have difficulties accessing transportation to visit, and information on agro-healing services is also insufficient (Roesta et al., 2010). In the Netherlands, there is a local agro-healing farm operation in almost all regions; information-sharing activities or workshops are held (Lee, 2016), and various efforts are being made to increase the accessibility of the agro-healing services.

Further, in the Netherlands, the United Kingdom, and Norway, agro-healing was included in the public service sector, and thus the system reduced the financial burden of agro-healing service costs for those receiving treatment by providing financial support (Hassink et al., 2014; Hassink and van Dijk, 2006; O'Connor et al., 2010; Parsons et al., 2010). This is regarded as the most important policy area that can increase access to agro-healing services, not only among members of the general public, but also for the socially disadvantaged who need treatment and rehabilitation.

In Europe, the professional workforce and institutions needed to run agro-healing farms have expanded. Europe has a well-developed agro-healing model; agro-healing farms are officially linked with various institutions such as schools, community service organizations, and hospitals, as these farms can provide new treatment resources to the local community, improve the emotional stability of consumers, and enable the economic maintenance of farms (Iacova and O'Connor, 2009; Goris and Dessein, 2007; Goris and Weckhuysen, 2007; Hine et al., 2008). The United Kingdom has established a regional linkage system for agro-healing, linking those who wish to be healed through close cooperation with organizations; they operate an agro-healing farm through the investment of a joint fund (CF UK, 2016). Government ministries have co-established a network to manage the quality of agro-healing farms (Hassink and van Dijk, 2006). Also, in Norway, a Green Care Council was established under government ministries to provide advice on agro-healing and to support various initiatives, such as quality control (Parsons et al., 2010).

Therefore, in order to improve the service quality performance and policies of domestic agro-healing farm operators, there is a need for policies that improve the efficiency of agro-healing farming. This can be achieved through the establishment of infrastructure between the agro-healing farm operator and related organizations and public institutions. In addition, it is thought that comprehensive support, such as the development and dissemination of agro-healing services, the enhancement of regional accessi- 


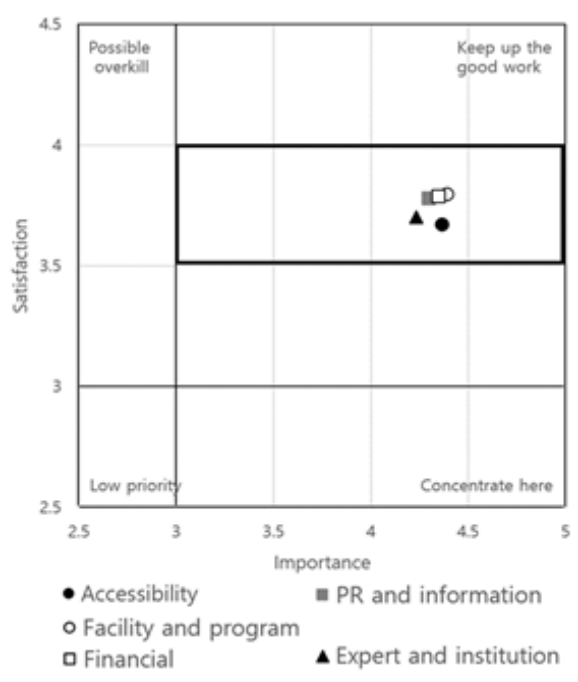

(a) All divisions

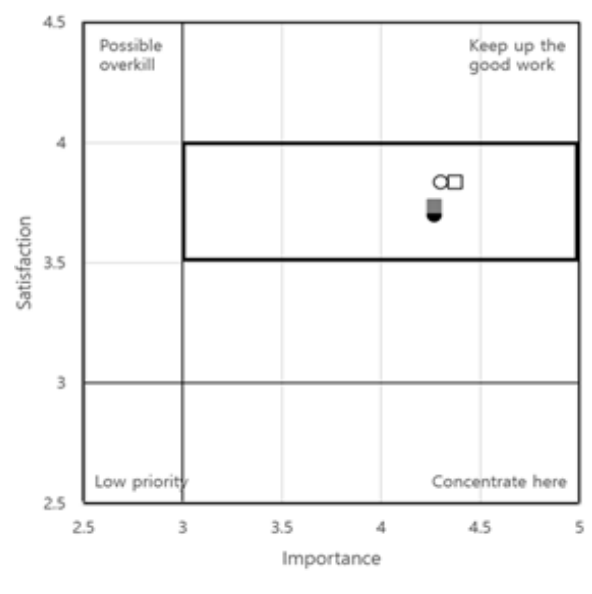

- Online media $\quad$ O Off-line media

O Facility information $\square$ Healing effect information

(c) Improving information promotion provision methods

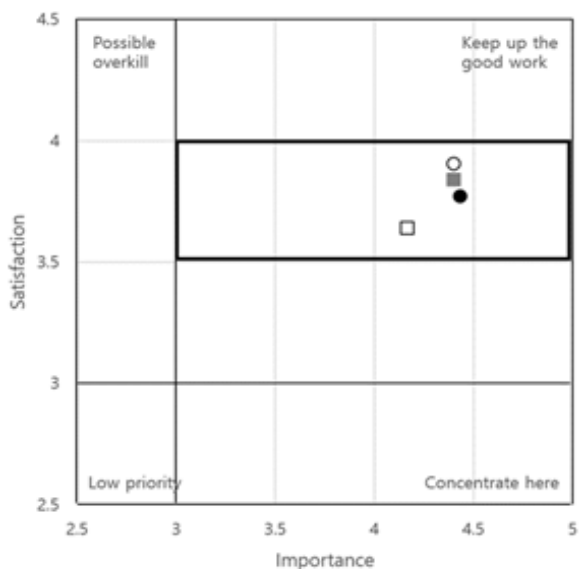

- Service charge

- Operating expeness

- Consulting and promotion $\square$ Facility operator

(e) Financial support

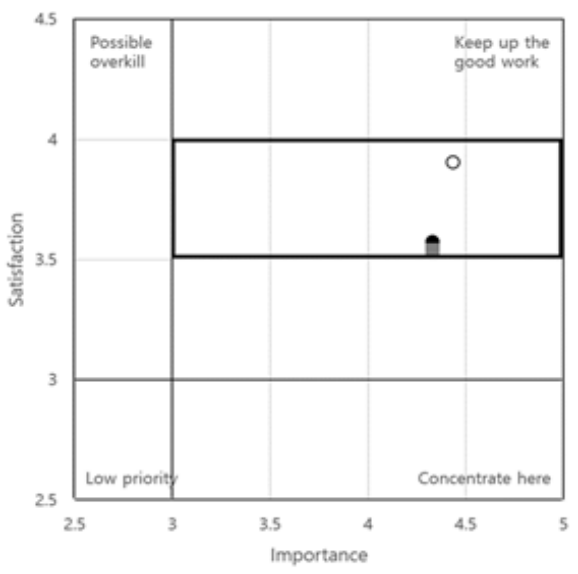

- Transportation $\quad$ B Barrier-free facility

- Convenient facility and parking lot

(b) Improving accessibility

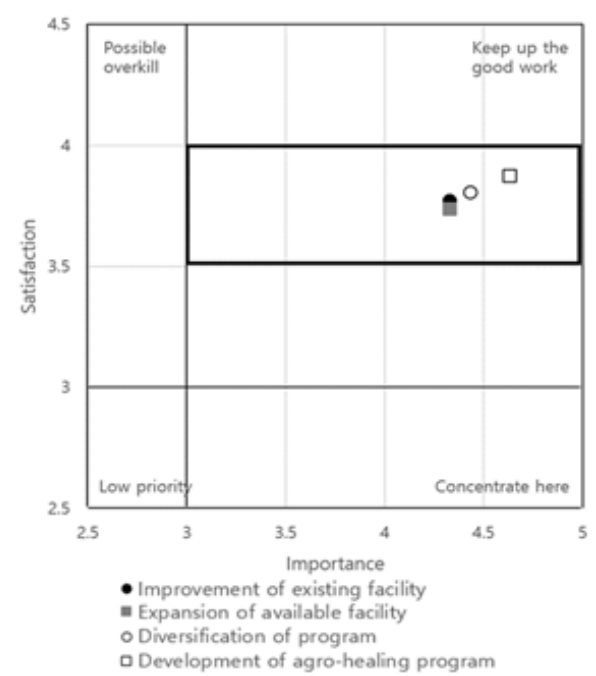

(d) Diversification of facilities and programs

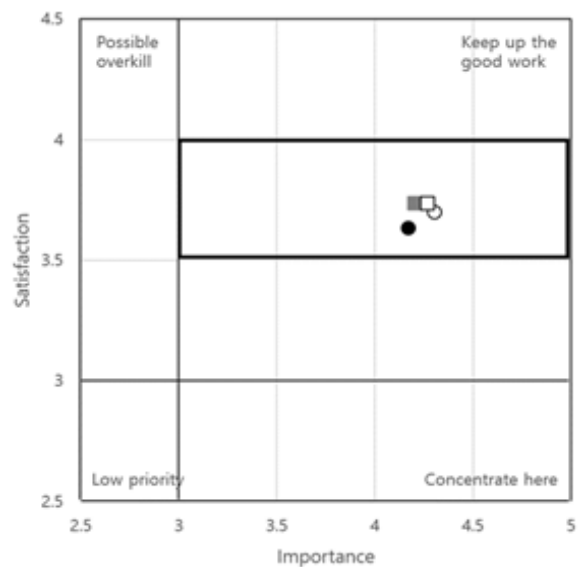

- Establishment of a specialized institution

- Estabishment of a specialized institus

- Professionallsm of employee in specialized institution

o Professionallsm of employee in operating facility

(f) Expansion of expert and specialized institutions

Fig. 2. Results of the IPA. 
bility, and increases in the type of publicity and information offered through the establishment of a support agency, should be provided.

\section{Conclusion}

In this study, a survey was administered to 30 domestic agro-healing farm owners to better understand their existing resources and to explore the available agro-healing farm service policies. The aim of this study was to collect preliminary data on the development of an agro-healing program to promote people's mental health. As a result, data on the operation/facility status of domestic agro-healing farms, as well as on the available environmental/ activity resources were collected. In addition, an IPA was performed and the findings were categorized as follows: improving accessibility, improving information promotion and provision methods, diversification of facilities and programs, financial support, and the expansion of expert and specialized institutions.

Domestic agro-healing farms have been converted from production farms or experiential farms; as such, it is necessary to identify and utilize the previous resources appropriately. The findings from this study highlighted that there is a need for education related to the establishment of domestic agro-healing facilities, the establishment of operating models, and the use of resources to inform program development and operations (Jeong et al., 2017; Lee et al., 2018b). In addition, this work does not stop once agro-healing farm resources have been identified, nor once agro-healing programs have been developed; rather, policy support should also be provided to agro-healing services through the formation of networks with local community organizations, as this would enhance accessibility, offer publicity, and increase access to information and needed supports.

In future research, a survey should be administered that targets a larger sample of domestic owners of agro-healing farms to ensure the representativeness of the survey sample. In addition, to activate the agro-healing service policies, it is necessary to expand the scope of the investigation and evaluate the service quality policies that target agro-healing consumers and experts in medicine and social welfare services. The results of this study are expected to inform the development and dissemination of domestic agro-healing programs, as well as the establishment of agro-healing policies and strategies.

\section{References}

Bae, S.J., S.J. Kim, and D.S. Kim. 2019. Priority analysis of activation policies for agro-healing services. J. Korean Soc. Rural Plan. 25(3):89-102. http://Dx.Doi.Org/10.7851/ Ksrp.2019.25.3.089

Bragg, R. 2013. Care farming in the UK-Key Facts and Figures. Summary report for Natural England: University of Essex, UK.

Care Farming UK (CF UK). 2016. Care farming in the UK and Ireland: State of play 2015.

Goris, K. and J. Dessein. 2007. Social farming in Flanders and Belgium. SoFar Project.

Goris, K. and H. Weckhuysen. 2007. Green care in Flanders. Presentation for Farming For Health CoP. Gent, Belgium.

Grönroos, C. 1984. A service quality model and its marketing implication. Eur. J. Mark. 18(4):36-44. https://doi:10. 1108/eum0000000004784

Hassink, J., H. Agricola, E.J. Veen, R. Pijpker, S.R. de Bruin, H.A. van der Meulen, and L.B. Plug. 2020. The care farming sector in the Netherlands: A reflection on its developments and promising innovations. Sustainability 12(9):3811. https://doi.org/10.3390/su12093811

Hassink, J. and M. van Dijk. 2006. Farming for health: Green-care farming across Europe and the United States of America (Vol. 13). Springer Science \& Business Media.

Hassink, J., W. Hulsink, and J. Grin. 2014. Farming with care: the evolution of care farming in the Netherlands. NJAS-Wagening J. Life Sci. 68:1-11. https://doi.org/10. 1016/j.njas.2013.11.001

Hine, R., J. Peacock, and J. Pretty. 2008. Care farming in the UK: Evidence and opportunities. Colchester, Essex: University of Essex.

Iacova, F.D. and D. O'Connor. 2009. Supporting policies for social farming in Europe: Progressing multifunctionality in responsive rural areas. "A journey through social farm- 
ing in Europe": the case studies (pp. 43-130). Italy: Press Service srl, Sesto Fiorentino (FI).

Jang, J.H., S.Y. Jung, H.Y. Kang, E.S. Lim, J.I. Lee, and S.M. Lee. 2021. SA study on agro-healing as a tourism resource healing experience tourism resources. J. Korean Soc. Rural Tour. 24(1):111-118

Jeong, S.J., J. Hassink, G.M. Gim, S.A. Park, and S.O. Kim. 2017. Status and actual condition analysis for current operational cases of care farms in South Korea. J. People Plants Environ. 20(5):421-429. https://doi.org/ 10.11628/ksppe.2017.20.5.421

Kozak, M. and M. Rimmington. 2000. Tourist satisfaction with Mallorca, Spain, as an off-season holiday destination. J. Travel Res. 38(3):260-269. https://doi:10.1177/0047287 50003800308

Lim, S.S. and J.E. Lim. 2017. Social Agriculture: A Paradigm Shift. KREI Current Issue Analysis No. 26.

Lee, A.Y., S.O. Kim, and S.A. Park. 2018a. Elementary school students' needs and preferences regarding urban agriculture. HortTechnology 28(6):783-794. https://doi.org/10.21273/HORTTECH04150-18

Lee, A.Y., Y.A. Oh, S.O. Kim, D.S. Kim, and S.A. Park. 2018b. Survey on demand and operation status of care farms in South Korea. J. People Plants Environ. 21:1-13. https://doi.org/10.11628/ksppe.2018.21.1.001

Lee, Y.J. 2016. Social agriculture in the Netherlands: Focusing on care farming. World Agric. 195:31-47.

Martilla, J.A. and J.C. James. 1977. Importance-performance analysis. J. Mark. 41(1):77-79. https://doi.org/10. 1177/002224297704100112

O'Connor, D., M. Lai, and S. Watson. 2010. Overview of social farming and rural development policy in selected EU member states. Eur. Netw. Rural Dev. 3.

Orel, F.D. and A. Kara. 2014. Supermarket self-checkout service quality, customer satisfaction, and loyalty: Empirical evidence from an emerging market. J. Retail. Consum. Serv. 21(2):118-129. https://doi:10.1016/j.jr etconser.2013.07.002
Park S.A., A.Y. Lee, G.J. Lee, W.L. Lee, S.J. Bae, B.J. Park, and D.S. Kim. 2017. A study of awareness and needs for care farming in South Korea. J. People Plants Environ. 20(1):19-24.

Parsons, S., D. Wilcox, and R. Hine. 2010. What care farming is? In Proceeding of the 9th European IFSA Symposium, 7 July 2010.

Roesta, A.E., S.J. Oostingb, T.F.Z. Reina, and J.F.C. Flinterman. 2010. Regional platforms for green care farming in the Netherlands. In Proceedings IFSA: Building sustainable rural futures. The added value of systems approaches in time of change and uncertainty, Vienna, Austria, 4-7 July, 2010 (pp. 306-314).

Rural Development Administration (RDA). 2012. A new function of agriculture, 'healing agriculture'. The Health and Organic Farming.

Rural Development Administration (RDA). 2017. Farmtype healing agricultural program development guide. Suwon, Korea: RDA. Retrieved from http://www.rda.go.kr

Rural Development Administration (RDA). 2020. Healing agriculture: Agricultural technology Gibbing 222. Suwon, Korea: RDA. Retrieved from http://www.rda.go.kr

Slack, N. 1994. The importance-performance matrix as a determinant of improvement priority. Int. J. Oper. Prod. Manag. 14(5):59-75. https://doi.org/10.1108/0144357941 0056803

Su, L., M.K. Hsu, and S. Swanson. 2017. The effect of tourist relationship perception on destination loyalty at a world heritage site in China: The mediating role of overall destination satisfaction and trust. J. Hosp. Tour. Res. 41(2):180-210. https://doi:10.1177/1096348014525630

Su, L., S.R., Swanson, and X. Chen. 2016. The effects of perceived service quality on repurchase intentions and subjective well-being of Chinese tourists: The mediating role of relationship quality. Tour. Manag. 52:82-95. https://doi:10.1016/j.tourman.2015.06.012 